\title{
Repetition of previously novel melodies sometimes increases both remember and know responses in recognition memory
}

\author{
JOHN M. GARDINER, ZOFLA KAMINSKA, and MAUREEN DIXON \\ City University, London, England \\ and \\ ROSALIND I. JAVA \\ Sussex University, Falmer, Brighton, England
}

\begin{abstract}
Recognition memory for previously novel melodies was tested in three experiments in which subjects used remember and know responses to report experiences of recollection, or of familiarity in the absence of recollection, for each melody they recognized. Some of the melodies were taken from Polish folk songs and presented vocally, but without the words. Others were taken from obscure pieces of classical music, presented as single-line melodies. Prior to the test, the melodies were repeated for varying numbers of study trials. Repetition of the Polish melodies increased both remember and know responses, while repetition of classical melodies increased remember but not know responses. When subjects were instructed to report guesses, guess responses were inversely related to remember and know responses and there were more guesses to lures than to targets. These findings establish that remembering and knowing are fully independent functionally and, by the same token, they provide further evidence against the idea that response exclusivity causes increases in remembering to force decreases in knowing. The findings also suggest that simultaneous increases in remembering and knowing occurred because the Polish melodies came from a genre for which the subjects had relatively little previous experience.
\end{abstract}

This article reports some findings from three experiments designed to investigate subjective states of awareness in recognizing previously novel musical excerpts. Though not yet fully understood, the findings are of theoretical interest because they demonstrate a relationship between measures of these states of awareness that has not been observed before, and they suggest that this relationship might depend on whether or not the music is of a kind, or genre, with which subjects are relatively familiar.

The measures are the remember and know responses introduced by Tulving (1985). In Tulving's theory, remember responses, which are reports of recollective experiences, measure autonoetic consciousness, the hallmark of an episodic memory system, and know responses, which are reports of knowledge of facts or events in the absence of recollective experiences, measure noetic consciousness, the hallmark of a semantic memory system (see too, e.g., Tulving, 1983, 1993). These measures have since been used to elucidate the nature of consciousness in a wide variety of memory phenomena (e.g., Conway \&

We thank Andrew Campion for collecting the data in Experiment 1, Alan Richardson-Klavehn for commenting on an earlier version of the manuscript, Paul Williams for technical assistance, and Dan Wright for statistical advice. This research was supported in part by a grant from the ESRC. Correspondence should be addressed to John Gardiner, Department of Psychology, City University, Northampton Square, London EC1V 0HB, U.K. (e-mail: j.m.gardiner@city.ac.uk).
Dewhurst, 1995; Dalla Barba, 1993; Gardiner, Gawlik, \& Richardson-Klavehn, 1994; Huron et al., 1995; Jones \& Roediger, 1995; LeComte, 1995; Mäntylä, 1993; Parkin \& Russo, 1993; Rajaram, 1993). They have been most frequently used in recognition memory, where they have also been related to dual-process theories that propose that recollection and familiarity provide separate, and independent, bases for recognition to occur (e.g., Jacoby, 1991).

The evidence so far is of several patterns of systematic dissociation and association between remember and know responses. Many variables that engage conceptual processing and elaborative rehearsal have large effects on remember responses and little effect on know responses. Some variables that engage perceptual processing and maintenance rehearsal have large effects on know responses and little effect on remember responses. Other variables-arguably, those that engage a tradeoff between both kinds of processing - have opposite effects on the two kinds of response (for reviews, see Gardiner \& Java, 1993; Rajaram \& Roediger, in press; Richardson-Klavehn, Gardiner, \& Java, 1996). The most recent evidence, however, shows that remember responses are influenced by perceptual factors (Rajaram, 1996) and that know responses are influenced by relational encoding (Mäntylä, 1996) and by conceptual learning (Conway, Gardiner, Perfect, \& Anderson, 1996).

The only possible relationship that has not been observed between remember and know responses is one in 
which both remember and know responses increase in parallel. Such an outcome would be of interest theoretically because it would provide evidence that the states of awareness measured by these responses were fully independent functionally, and also because of assumptions that had been made about the relationship between the underlying hypothetical processes. Jacoby, Yonelinas, and Jennings (in press) equate the states of awareness with the underlying process and argue that recollection and familiarity are independent, which means that recollection is sometimes accompanied by familiarity, sometimes not. Remember and know responses are exclusive, and so Jacoby et al. proposed an independence remember/know model in which remember responses provide estimates of recollection and familiarity is estimated by the proportion of know responses divided by 1 minus the proportion of remember responses. This brings the remember/ know procedure into line with the way estimates are obtained in Jacoby's (1991) process dissociation procedure. Jacoby et al. also suggested that because of the exclusivity of remember and know responses, increases in remember responses might force decreases in know responses (for more discussion, see Gardiner, Java, \& RichardsonKlavehn, 1996; Richardson-Klavehn et al., 1996). Any evidence that know responses can increase at the same time that remember responses increase would therefore be interesting in this connection, even if the reasons for that outcome were not yet fully understood.

The experiments followed up previous experiments by Java, Kaminska, and Gardiner (1995), that measured awareness in recognition memory for music. Java et al. compared the recognition of obscure excerpts from classical music with that of excerpts from such famous pieces as Für Elise and the 1812 overture. Recognition measured by remember responses was much greater for the famous than for the obscure music, but this variable had little effect on recognition measured by know responses. Unlike those previous experiments, the present experiments involved only music subjects had never heard before, and what was varied was the number of opportunities the subjects had to listen to this music before the recognition test. It was expected that listening to the music repeatedly would increase recollection, measured by remember responses, because it would provide more opportunity to encode novel music in an elaborative way (see Java et al., 1995). At issue was whether additional opportunities to listen to such music might also increase familiarity measured by know responses.

\section{EXPERIMENT 1}

In Experiment 1, the musical excerpts were all taken from Polish folk songs, and they were presented, without words, in a female voice. None of the subjects had had any previous experience with music of this sort. Three groups of subjects heard these excerpts once, twice, or four times in successive study trials, before receiving the recognition test.

\section{Method}

Subjects. The subjects were 36 undergraduate students at City University, London, who were tested individually and were paid for their participation. The subjects were allocated randomly to one of three groups of 12

Design and Materials. There was one between-subjects factor, the number of times musical excerpts were successively presented before a recognition test. The music was presented once, twice, or four times to three groups of 12 subjects. The musical excerpts were taken from Polish folk songs and recorded by one female voice singing "la-la." They were on average about 15-16 notes in length, ranging from 7 to 22 notes. They were recorded on a Casio CZ1 synthesizer and then transferred to Sony cassettes for playing back to subjects. The effect, musically, was strange - at least, to English subjects - rather like that of listening to a wordless lullaby, or dirge, with little obvious melodic structure. There were 48 excerpts, but only 24 excerpts were included in any study list. Within each group, half of the subjects studied one list of 24 excerpts, the other half studied a list of the other 24 excerpts. The entire study list was repeated once, twice, or four times. There followed a single recognition test containing all 48 excerpts, and the subjects had to identify the excerpts they had heard earlier and to provide remember or know responses.

Procedure. From a single original recording of each melody, one recognition test list was constructed in which all $\mathbf{4 8}$ melodies occurred in a random order and each melody was preceded by its numbered position in the test list, for subjects to write their test responses on a correspondingly numbered response sheet. The original recording was then further edited to create the study lists. Each of the two alternative study lists was created by randomly dividing the 48 excerpts into two lists of 24. These lists were then each edited into four different random orders for presentation. Each of these random orders was used equally often in each of the three groups of subjects, and these differently ordered lists were fully counterbalanced across study trials. The average duration of each excerpt was about $7.5 \mathrm{sec}$, and the average time between excerpts was about $5 \mathrm{sec}$, so each list took about 5 min to present.

The recognition test took place directly after the study phase. The subjects were given a numbered response sheet and wrote down their responses after hearing each excerpt that was presented. They circled the number of any excerpt they recognized, and then wrote an " $R$ " for remember or a " $K$ " for know; they wrote an " $X$ " to indicate they did not recognize the music. The test instructions were closely modeled on those used in previous studies, but additionally adapted for music (see, too, Java et al., 1995). After being generally instructed about the two states of awareness that are associated with recognition memory, the subjects were told:

The same kinds of awareness are associated with recognising music. Some-
times, in recognising a piece of music, you remember something that you
thought about when you heard the music before. You experience again some-
thing you experienced at that time. But sometimes recognising a piece of
music involves strong feelings of familiarity in the absence of any recollec-
tive experience.

The recognition test was self-paced. The subjects were told not to guess. The whole experiment took about $25 \mathrm{~min}$ for the one-trial group, $35 \mathrm{~min}$ for the two-trial group, and $50 \mathrm{~min}$ for the four-trial group.

\section{Results and Discussion}

The principal results are summarized in Table 1, which shows the proportions of hit rates and of hit rates minus false alarms, as a function of study trials. False-alarm rates were quite high and variable, but the general trend is readily apparent: Recognition increased with increasing study trials for both states of awareness. There was little evidence of this trend in remember hit rates, but that particular outcome turned out not to be replicable in subsequent experiments and is probably related to the exceptionally high false-alarm rate after one trial. Statistical analyses of the data were carried out separately for remem- 
Table 1

Proportion of Responses for Each State of Awareness as a Function of Study Trials in Experiment 1

\begin{tabular}{lccccccc}
\hline & \multicolumn{3}{c}{ Hits } & & \multicolumn{3}{c}{ Hits Minus False Alarms } \\
\cline { 2 - 4 } Responses & 1 Trial & 2 Trials & 4 Trials & & Trial & 2 Trials & 4 Trials \\
\hline Remember & $.30(.13)$ & $.29(.04)$ & $.33(.02)$ & .17 & .25 & .31 \\
Know & $.29(.18)$ & $.38(.16)$ & $.52(.11)$ & .11 & .22 & .41 \\
Overall & $.59(.31)$ & $.67(.20)$ & $.85(.13)$ & .28 & .47 & .72 \\
\hline
\end{tabular}

Note-False-alarm rates are shown in parentheses.

ber and know responses. The alpha level was set at .05 throughout. Analyses of the hit rates showed significant trials effects for know responses $\left[F(2,33)=8.45, M S_{\mathrm{e}}=\right.$ $.02]$ but not for remember responses $\left[F(2,33)<1, M S_{\mathrm{e}}=\right.$ $.01]$. Analyses of hit rates minus false-alarm rates showed a significant trials effects for both know $[F(2,33)=$ $\left.16.37, M S_{\mathrm{e}}=.02\right]$ and remember $\left[F(2,33)=4.32, M S_{\mathrm{e}}=\right.$ $.01]$ responses.

\section{EXPERIMENT 2}

The results of Experiment 1 showed that additional opportunities to listen to previously novel melodies improved recognition memory as measured by both remember and know responses. The aim of Experiment 2 was to test the generalizability of these results. In most essential respects, this experiment was similar to Experiment 1, except for the use of a different set of materials. Instead of being taken from Polish folk songs, the excerpts were taken from obscure pieces of classical music.

\section{Method}

Subjects. The subjects were a further sample of 36 undergraduate students at City University, London, who were tested individually and were paid for their participation. They were allocated randomly to one of three groups of 12 .

Design, Materials, and Procedure. The design and procedure were exactly the same as those in Experiment 1 , but the music was different. A set of 48 themes from obscure pieces of classical music was selected from Barlow and Morgenstern's (1983) Dictionary of Musical Themes (see, too, Java et al., 1995). Nearly all these themes were from keyboard pieces; a few were from pieces for other solo instruments or from chamber music. The composers ranged from Bach to Bruckner (historically, not alphabetically). The average length of the themes was about 12-13 notes, ranging from 8 to 21 , and their average duration and the interval between them were about the same as those of the Polish folk songs. They were all recorded by a pianist as single line melodies on a Casio CZ1 synthesizer and then transferred to Sony cassettes for playing back to subjects. The effect, musically, was different from that in Experiment 1 . There was more variety in rhythm and pitch and, to English subjects, the themes sounded more tuneful than the excerpts from Polish folk songs

\section{Results and Discussion}

The principal results are summarized in Table 2, which shows the proportions of hit rates and of hit rates minus false alarms, as a function of study trials. At first sight, the general trends here seem similar to those in Table 1, except for the marked increase in the hit rates for remember responses. But the increase in know responses is actually much reduced, in comparison with Experiment 1 , especially in hit rates. Comparable statistical analyses to those used for Experiment 1 were undertaken for the present results. For the hit rates, the trials effect was significant for remember responses $[F(2,33)=$ $\left.3.51, M S_{\mathrm{e}}=.03\right]$ but not for know responses $[F(2,33)=$ $\left.2.46, M S_{\mathrm{e}}=.02\right]$. For hit rates minus false-alarm rates, the trials effect was also significant for remember $\left[F(2,33)=6.54, M S_{\mathrm{e}}=.03\right]$ but not for know responses $\left[F(2,33)=1.26, M S_{\mathrm{e}}=.02\right]$.

\section{EXPERIMENT 3}

The major conclusion from Experiment 2 is that additional opportunities to listen to these previously novel melodies improved recognition memory only as measured by remember responses, not as measured by know responses (although some increase was evident, particularly in hit rates). This outcome contrasts with the results of Experiment 1 , where recognition memory improved in know as well as in remember responses, and it was not what we had expected. Therefore, the aim of Experiment 3 was to confirm the empirical facts by endeavoring to replicate both kinds of result within one and the same experiment. In this experiment, the subjects were presented with both kinds of music used in Experiments 1 and 2 in a single, mixed list. Several other changes were made. The trials factor was reduced to two levels. Subjects had either one or three study trials. And they were instructed additionally to report guesses.

Gardiner et al. (1996; see also, Jacoby et al., in press; Strack \& Forster, 1995) have discussed the problems that arise when subjects include in their know responses responses that are really guesses, in the sense that subjects may sometimes select targets when they have the experience neither of remembering nor of knowing. Gardiner et al. showed that when subjects are additionally allowed to report guessing, guess responses, but not know responses, are inversely related to remember responses. Moreover, when subjects reported guessing, the likelihood of their selecting targets did not exceed the likelihood of their selecting lures. That is, unlike either remember or know responses, guess responses indicated no memory for the study episode. The inclusion of guess responses in Experiment 3 should therefore additionally provide a test of the replicability of those findings.

\section{Method}

Subjects. The subjects were a further 36 undergraduate students at City University, London, who were tested individually and were paid for their participation. They were allocated randomly into two groups of 18 .

Table 2

Proportion of Responses for Each State of Awareness as a Function of Study Trials in Experiment 2

\begin{tabular}{lccccccc}
\hline & \multicolumn{3}{c}{ Hits } & & \multicolumn{3}{c}{ Hits Minus False Alarms } \\
\cline { 2 - 4 } Responses & 1 Trial & 2 Trials & 4 Trials & & 1 Trial & 2 Trials & 4 Trials \\
\hline Remember & $.25(.08)$ & $.27(.03)$ & $.42(.01)$ & .17 & .24 & .41 \\
Know & $.32(.09)$ & $.46(.13)$ & $.38(.07)$ & .23 & .33 & .31 \\
Overall & $.57(.17)$ & $.73(.16)$ & $.80(.08)$ & .40 & .57 & .72 \\
\hline
\end{tabular}

Note-False-alarm rates are shown in parentheses. 
Design, Materials, and Procedure. In many respects, the experiment was similar to the two previous experiments, and here we describe only important differences. One group of subjects received one study trial; the other group received three study trials. The materials were an arbitrary selection from those used in Experiments 1 and 2, and consisted of 30 excerpts from Polish folk songs and 30 themes from obscure pieces of classical music. The original recordings were used, but reedited to construct new study and test lists in which the Polish and classical excerpts were mixed together. The recognition test consisted of a single, numbered order of all 60 musical phrases. Two alternative study lists of 30 excerpts were created by randomly dividing each kind of music into two subsets of 15 excerpts and recombining them. Further editing produced three random orders of each study list. Subjects who had three successive study trials heard all three orders, and these orders were counterbalanced across the trials for different subjects. Each order of presentation was used equally often across successively tested subjects in the single study-trial group. The test was similar to that in the previous experiments except that, instead of telling subjects not to guess, they were told to report guesses as a separate response category. The critical addition to the previous instructions was as follows:

There will also be times when you do not remember a theme, nor does it seem familiar, but you might want to guess that it was one of the themes you heard earlier. On these occasions please indicate that you are guessing by writing a G. There are nearly always more themes than one is capable of recognizing, so do feel free to take a guess.

The whole experiment took about $25 \mathrm{~min}$ for the one-trial group and about $\mathbf{4 5} \mathrm{min}$ for the three-trial group.

\section{Results and Discussion}

The principal results are summarized in Table 3, which shows the proportions of hit rates and of hit rates minus false alarms, as a function of study trials for each of the two kinds of music. Two major sets of findings are readily apparent in Table 3. First, these data replicate the results of Experiments 1 and 2. For the excerpts from Polish folk songs, additional study trials improved recognition memory, as measured by both remember and know responses. For the themes from pieces of classical music, additional study trials improved recognition memory, as measured by remember responses but not as measured by know responses.

Second, these data replicate the results reported by Gardiner et al. (1996) by showing that it was guessing, not knowing, that is inversely related to the proportion of remember responses to target items. These data extend that finding by also showing that guessing is inversely

Table 3

Proportion of Responses for Each State of Awareness as a Function of Study Trials in Experiment 3

\begin{tabular}{lccccc}
\hline & \multicolumn{2}{c}{ Hits } & & \multicolumn{2}{c}{ Hits Minus False Alarms } \\
\cline { 2 - 3 } Responses & 1 Trial & 3 Trials & & 1 Trial & 3 Trials \\
\hline \multirow{3}{*}{ Remember } & $.23(.04)$ & Polish & $.37(.04)$ & .19 & .33 \\
Know & $.21(.12)$ & $.34(.13)$ & .09 & .21 \\
Guess & $.31(.33)$ & $.19(.32)$ & -.02 & -.13 \\
Overall & $.75(.49)$ & $.90(.49)$ & .26 & .41 \\
& & Classical & & \\
Remember & $.21(.04)$ & $.45(.06)$ & .17 & .39 \\
Know & $.33(.14)$ & $.31(.13)$ & .19 & .18 \\
Guess & $.23(.27)$ & $.14(.21)$ & -.04 & -.07 \\
Overall & $.77(.45)$ & $.90(.40)$ & .32 & .50 \\
\hline
\end{tabular}

Note-False-alarm rates are shown in parentheses. related to the proportion of know responses to target items. Know responses to targets did not vary in the experiments described by Gardiner et al. The general implication of this aspect of the data is that, at least when ceiling effects are avoided, it is only the opportunity to guess that is constrained by the proportions either of remember responses or of know responses. And this constraint can lead to "negative discrimination" effects, where guess responses to lures exceed guess responses to targets when hit rates are high, as they were after three trials.

Statistical analyses of the data, in which trials ( 1 vs. 3 ) and materials (Polish vs. classical music) were fixed factors, supported these conclusions. For hit rates with remember responses, there was a significant effect of trials $\left[F(1,34)=10.41, M S_{\mathrm{e}}=.06\right]$ but neither the materials effect nor the interaction were significant $(F<1$ in each case). For hit rates with know responses, neither the effect of trials $\left[F(1,34)=2.01, M S_{\mathrm{e}}=.03\right]$ nor the materials effect $\left[F(1,34)=1.22, M S_{\mathrm{e}}=.02\right]$ were significant, but the interaction was $\left[F(1,34)=4.64, M S_{\mathrm{e}}=\right.$ $.02]$. Planned comparisons confirmed that there was a significant trials effect in know responses for the Polish music $[t(34)=3.28]$ and not for the classical music $(t<1)$. For hit rates with guess responses, there was a significant trials effect $\left[F(1,34)=3.80, M S_{\mathrm{e}}=.05\right]$ and a significant materials effect $\left[F(1,34)=7.72, M S_{\mathrm{e}}=\right.$ $.01]$; the interaction was not significant $(F<1)$.

For hit rates minus false-alarm rates, with remember responses there was a significant effect of trials $[F(1,34)=$ $10.71, M S e=.05]$ but neither the effect of materials nor the interaction were significant ( $F<1$ in each case). With know responses, the corrected data were skewed, and parametric tests were not appropriate. But MannWhitney tests confirmed that there was a significant trials effect for the Polish music $[U(18)=102.5]$ and not for the classical music $[U(18)=153.0$; critical $U=109]$. There was little point in analyzing hit rates minus falsealarm rates for guess responses.

\section{GENERAL DISCUSSION}

These experiments establish that there are circumstances in which there are parallel improvements in recognition as measured by both remember and know responses. The theoretical significance of the parallel increase in remembering and knowing is that it is evidence that, functionally, these two states of awareness are fully independent. That is, all possible kinds of empirical relation between the two states of awareness have now been observed. There are variables that affect remembering, not knowing, variables that affect knowing, not remembering, variables that have opposing effects on remembering and knowing, and now at least one variable - study trials - that under certain conditions has the same effect on remembering and knowing.

Experiment 3 also shows that guessing is inversely related not only to increases in remembering, but also to increases in knowing. It shows that any dependency that exists empirically between the different response categories exists between remembering and guessing and between knowing and guessing, but not between remembering and knowing. This conclusion will of course hold only within certain limits. Very high levels of remember responses could well constrain know responses, and researchers using this procedure still need to take especial care to avoid such ceiling effects, at least if any strong theoretical argument hangs on what happens to know responses. 
In this connection, it is of interest that guess responses showed negative discrimination effects. Jacoby et al. (in press) discussed similar effects in their estimates of familiarity, which were based on analyses in which know responses to targets were combined with know responses to lures. They interpreted such effects to mean that the lures had become more familiar than targets, a pattern of results that they concluded was unreasonable and which they attributed to the exclusivity of remember and know responses. Our evidence suggests that one could obtain such effects by encouraging subjects to guess and by not allowing them to report guesses as such, forcing them to include these guesses in their know responses (see, too, Gardiner et al., 1996; Strack \& Forster, 1995).

Why, when subjects reported guesses, were there still relatively high levels of false alarms for know responses? These false alarms might at least in part reflect the way in which excerpts of music often contain very similar musical phrases, if the excerpts are broken down into two- or three-note runs. Thus, fragments of any given excerpt might very well give rise to feelings of familiarity based on the similarity between fragments of music contained in targets and lures. Very occasionally, lures might, for the same reason, give rise to some recollective experiences.

Applying the independence remember/know model proposed by Jacoby et al. (in press) to the data in Table 3 would lead to the conclusion that estimates of the hypothetical familiarity process increase over trials for both kinds of music, and that the increase is much greater for the Polish (estimates of .27 and .54) than for the classical (estimates of .42 and .56) music. If, however, remember and know responses are functionally independent, then it is not clear why know responses need to be "corrected" for a presumed lack of independence-unless one subscribes to that particular process model. In contrast with the process dissociation procedure, our approach is largely a descriptive one, in which the aim is to discover what factors influence the states of awareness, and it allows relations between the states of awareness to differ from relations between the processes (or systems) that are assumed to underlie them (see, e.g., Gardiner \& Java, 1993; Richardson-Klavehn et al., 1996). For example, states of awareness may be exclusive, but this does not necessarily mean that the underlying processes are-they might be exclusive too (Gardiner \& Parkin, 1990), but they might be independent or redundant (see Richardson-Klavehn et al., 1996, for more discussion; see, too, Knowlton \& Squire, 1995). In Tulving's (1995, in press) SPI systems model, encoding into different systems is serial, storage is parallel, and retrieval is independent. Similarly, RichardsonKlavehn et al. (1996) have argued that though exclusivity may hold for relations between different memorial states of awareness, retrieval strategies, which can be voluntary or involuntary with respect to retrieval of the study episode, may well be independent (see Java, 1994 Richardson-Klavehn \& Gardiner, 1995, 1996; Richardson-Klavehn, Gardiner, \& Java, 1994). Because it is a simple two-component model, the process dissociation procedure cannot make these kinds of distinctions.

Why recognition memory measured by know responses increases across study trials with one kind of musical excerpt but not the other is a question for future research. Certain explanations seem unlikely. For example, proportions of know false alarms in Table 3 were quite similar for each kind of music, suggesting that the different effects in know responses to targets cannot be related to differences in subjects' response criteria. It is also possible that the critical difference between the two kinds of music might lie in the way they were presented, either vocally or from a keyboard. But there is no obvious reason why that might be so. And the proportions of remember responses for the Polish and the classical music did not differ statistically, so the different effects on know responses for the two kinds of music cannot be related to significant differences in the overall amount of recollection.

However, there were more remember responses for classical music than for Polish music on the final trials, and it is possible to argue that this could "artificially constrain" the know responses. Though plausible, this argument disregards the evidence that shows it was the guess responses that were constrained. Moreover, Gardiner et al. (1996, Experiment 1) found that even with much higher proportions of remember responses and a much larger effect on remember responses, only guess responses seemed constrained. For the two level-of-processing conditions in this experiment, hit rates were .15 and .72 for remember responses, .20 and .18 for know responses, and .24 and .05 for guess responses. Those results, together with the present results, imply that there was scope for a further increase in know responses for the classical music and that such an increase would have still further depressed guess responses in Experiment 3. If that supposition is mistaken, then one obvious implication is that the nonsignificant increase in know responses observed in Experiment 2 should become more pronounced if the proportion of remember responses were lower. But our provisional conclusion is that the overall level of responding was not the critical factor

So our conjecture - and it is no more than that--is that the dissociation in know responses may reflect the prior familiarity of the musical genre as a whole. In comparison with classical music, there is likely to be little schematic representation in semantic memory for Polish folk songs, and the effect of increased learning opportunity is likely to result in, or at least initiate, the formation of such representations (cf. Bartlett, Halpern, \& Dowling, 1995; Conway et al., 1996; see, too, Sloboda \& Parker, 1985). Consistent with this possibility, the data in Table 3 show that the level of know responses was quite similar after three trials for both kinds of music, and the increase in know responses for the Polish music was associated with a relatively low initial level of performance. This increase in know responses may be a direct reflection of increased schematic representation. Also consistent with this possibility is the earlier finding that know responses did not differ in comparing famous with obscure pieces of classical music (Java et al., 1995). But whether there is any substance to this conjecture remains to be resolved. For now, the important fact is that there are at least some circumstances in which both remembering and knowing increase in parallel.

\section{REFERENCES}

Barlow, H., \& Morgenstern, R. (1983). A dictionary of musical themes. London: Faber \& Faber

Bartlett, J. C., Halpern, A. R., \& Dowling, W. J. (1995). Recognition of familiar and unfamiliar melodies in normal aging and Alzheimer's disease. Memory \& Cognition, 23, 531-546.

Conway, M. A. \& Dewhurst, S. J. (1995) The self and recollective experience. Applied Cognitive Psychology, 9, 1-19.

Conway, M. A., Gardiner, J. M., Perfect, T. J., \& Anderson, S. J. (1996). States of memory awareness as an index of learning: The acquisition of knowledge by 1st-year psychology undergraduates. Manuscript submitted for publication.

Dalla Barba, G. (1993). Confabulation: Knowledge and recollective experience. Cognitive Neuropsychology, 10, 1-20.

Gardiner, J. M., GaWlik, B., \& Richardson-KLaVehn, A. (1994). Maintenance rehearsal affects knowing, not remembering; elaborative rehearsal affects remembering, not knowing. Psychonomic Bulletin \& Review, 1, 107-110.

GARDINER, J. M., \& JAVA, R. I. (1993). Recognizing and remembering. In A. Collins, M. A. Conway, S. E. Gathercole, \& P. E. Morris (Eds.), Theories of memory (pp. 85-158). Hillsdale, NJ: Erlbaum.

Gardiner, J. M., JAVA, R. I., \& RichaRdSON-KLAVEHN, A. (1996). How level of processing really influences awareness in recognition memory. Canadian Journal of Experimental Psychology, 50, 114-122.

Gardiner, J. M., \& PARKIN, A. J. (1990). Attention and recollective experience in recognition memory. Memory \& Cognition, 18, 579-583.

Huron, C., Danion, J.-M., Giacomoni, F., Grange, D., Robert, P., \& Rizzo, L. (1995). Schizophrenia impairs recognition memory with, but not without, conscious recollection. American Journal of Psychiatry, 152, 513-541.

JACOBY, L. L. (1991). A process dissociation framework: Separating automatic from intentional uses of memory. Journal of Memory \& Language, 30, 513-541.

JACOBY, L. L., Yonelinas, A. P., \& Jennings, J. M. (in press). The relation between conscious and unconscious (automatic) influences: A declaration of independence. In J. D. Cohen \& J. W. Schooler (Eds.), Scientific approaches to the question of consciousness. Hillsdale, NJ: Erlbaum.

$J_{A V A}, R$. I. (1994). States of awareness following word stem completion. European Journal of Cognitive Psychology, 6, 77-92.

JaVA, R. I., Kaminska, Z., \& Gardiner, J. M. (1995). Recognition memory and awareness for famous and obscure musical themes. European Journal of Cognitive Psychology, 7, 41-53.

JONES, T. C., \& RoEDigER, H. L., III (1995). The experiential basis of se- 
rial position effects. European Journal of Cognitive Psychology, 7 , 65-80.

KNOWLTON, B. J., \& SQuiRe, L. R. (1995). Remembering and knowing: Two different expressions of declarative memory. Journal of Experimental Psychology: Learning, Memory, \& Cognition, 21, 699-710.

LECOMTE, D. (1995). Recollective experience in the revelation effect: Separating the contributions of recollection and familiarity. Memory \& Cognition, 23, 324-334.

MÄNTYLÄ, T. (1993). Knowing but not remembering: Adult age differences in recollective experience. Memory \& Cognition, 21, 379-388.

MÄNTYLÄ, T. (1996). Recollections of faces: Remembering differences and knowing similarities. Manuscript submitted for publication.

PARKIN, A. J., \& Russo, R. (1993). On the origin of functional differences in recollective experience. Memory, 1, 231-237.

RaJARAM, S. (1993). The components of recollective experience: Remembering and knowing. Memory \& Cognition, 21, 89-102.

Rajaram, S. (1996). Perceptual effects on remembering: Recollective processes in picture recognition memory. Journal of Experimental Psychology: Learning, Memory, \& Cognition, 22, 365-377.

Rajaram, S., \& Roediger, H. L., III (in press). Remembering and knowing as states of consciousness during recollection. In J. D. Cohen \& J. W. Schooler (Eds.), Scientific approaches to the study of consciousness. New York: Erlbaum.

RichaRdSON-KlaVehn, A., \& GardinER, J. M. (1995). Retrieval volition and memorial awareness in stem completion: An empirical analysis. Psychological Research, 57, 166-178.

RichaRdSON-KLAVEHN, A., \& GARDINER, J. M. (1996). Cross-modality priming in stem completion reflects conscious memory, but not voluntary memory. Psychonomic Bulletin \& Review, 3, 238-244.
Richardson-Klavehn, A., Gardiner, J. M., \& JaVa, R. I. (1994). Involuntary conscious memory and the method of opposition. Memory, 2, 1-29.

Richardson-Klavehn, A., Gardiner, J. M., \& Java, R. I. (1996) Memory: Task dissociations, process dissociations, and dissociations of consciousness. In G. Underwood (Ed.), Implicit cognition (pp. 85-158). Oxford: Oxford University Press.

Sloboda, J. A., \& PARKer, D. H. H. (1985). Immediate recall of melodies. In P. Howell, I. Cross, \& R. West (Eds.), Musical structure and cognition (pp. 143-167). New York: Academic Press.

STRACK, F., \& FORSTER, J. (1995). Reporting recollective experiences: Direct access to memory systems? Psychological Science, 6, 352358.

Tulving, E. (1983). Elements of episodic memory. New York: Oxford University Press.

Tulving, E. (1985). Memory and consciousness. Canadian Psychologist, 26, 1-12.

TulviNG, E. (1993). What is episodic memory? Current Directions in Psychological Sciences, 2, 67-70.

Tulving, E. (1995). Organization of memory: Quo vadis? In M. S. Gazzaniga (Ed.), The cognitive neurosciences (pp. 839-847). Cambridge, MA: MIT Press.

Tulving, E. (in press). Episodic memory: From mind to brain. The 21 st Bartlett lecture. Quarterly Journal of Experimental Psychology.

(Manuscript received November 27, 1995; revision accepted for publication April 3, 1996.) 